\title{
Therapeutic Angiogenesis for Severely Ischemic Limbs - from Bench to Bedside in Acute Vascular Care
}

\author{
Theodora Benedek ${ }^{1,2}$, István Kovács ${ }^{1,2}$, Imre Benedek ${ }^{1,2}$ \\ ${ }^{1}$ University of Medicine and Pharmacy, Tîrgu Mureș, Romania \\ ${ }^{2}$ Center of Advanced Research in Multimodality Cardiac Imaging, Cardio Med Medical Center, Tîrgu Mureș, Romania
}

\begin{abstract}
Severe limb ischemia represents a critical condition, being associated with high morbidity and mortality rates. Patients with critical limb ischemia (CLI) require urgent initiation of interventional or surgical treatment, as restoration of the blood flow is the only way to ensure limb salvage in these critical cases. At the same time, in acute limb ischemia, a dramatic form of sudden arterial occlusion of the lower limbs, the integrity of the limb is also seriously threatened in the absence of urgent revascularization. From patients with CLI, 40\% are "no option CLI", meaning patients in whom, due to anatomical considerations or to the severity of the lesions, there is no possibility to perform interventional or surgical treatment or they have failed. Therapeutic angiogenesis has been proposed to serve as an effective and promising alternative therapy for patients with severe limb ischemia who do not have any other option for revascularization. This review aims to present the current status in therapeutic angiogenesis and the role of different approaches (gene or cell therapy, intra-arterial vs. intramuscular injections, different sources of cells) in increasing the rates of limb salvage in patients with severe ischemia of the lower limbs.
\end{abstract}

Keywords: arterial occlusion, stem cells, limb salvage, amputation, acute limb ischemia

\section{ARTICLE HISTORY}

Received: May 21, 2017

Accepted: October 25, 2017

\section{CORRESPONDENCE}

István Kovács

Str. Gheorghe Marinescu nr. 38

540139 Tîrgu Mureș, Romania

Tel: +40 265215551

E-mail: kov_istvan@yahoo.com

\section{INTRODUCTION}

Severe limb ischemia represents a critical condition, being associated with high morbidity and mortality rates. ${ }^{1-4}$ Critical limb ischemia (CLI) is usually caused by one or multiple occlusions in the peripheral arteries of the lower limbs and results from the progressive evolution of a chronic peripheral arterial disease to a stage in which the viability of the affected limb is seriously threatened..$^{5-7}$
In this case, the condition becomes a vascular emergency, as prompt initiation of adequate therapeutic measures restoring the blood flow is the only way to ensure limb salvage. ${ }^{8-10}$ At the same time, severe ischemia can represent the clinical manifestation of acute limb ischemia, a dramatic form of sudden arterial occlusion of the lower limbs, in which the integrity of the limb is seriously threatened in the absence of urgent revascularization. ${ }^{11-12}$ 
Acute limb ischemia, defined as ischemia of the lower extremities lasting no longer than 14 days, has a reported 1 -year mortality rate of over $40 \%$ and is 20 times more common in the lower limbs than in the upper extremities. ${ }^{13}$

Unfortunately, $50 \%$ of CLI patients do not present any symptoms 6 months prior to the onset of CLI, which makes it difficult to establish an effective preventive strategy. ${ }^{14,15}$ The prognosis associated with CLI is extremely severe in the absence of flow restoration, with a 1-year mortality of $20 \%$ and a 1-year amputation rate of 40\%.14,16,17 From patients with CLI, $25 \%$ progress each year to limb amputation, while $40 \%$ of patients are "no option CLI". ${ }^{14,18}$ The class of "no option CLI patients" represents a group of patients in whom, due to anatomical considerations or to the severity of the lesions, there is no possibility to perform interventional or surgical treatment or they have failed. Despite the recent progresses encountered in interventional devices, in a significant number of cases interventional therapy still fails to reopen the occluded peripheral arteries. ${ }^{19-22}$

Therapeutic angiogenesis via cellular transplantation has been proposed to serve as an effective and promising alternative therapy for the treatment of patients with severe limb ischemia who have no other option for revascularization. ${ }^{23-31}$

\section{THERAPEUTIC ANGIOGENESIS - A NEW CONCEPT IN VASCULAR CARE}

Therapeutic angiogenesis has been introduced in recent years as an alternative for limb salvage in patients with occluded peripheral arteries, based on the concept that formation of new vessels is possible via vasculogenesis, angiogenesis, and arteriogenesis, and these new vessels would be able to replace the function of the occluded arteries and to ensure an adequate supply of oxygen in severely ischemic tissues. ${ }^{14,32-35}$

Vasculogenesis and angiogenesis are complex processes that lead to the formation of new capillaries, being controlled by numerous soluble growth factors, inhibitors, cytokines, adhesion molecules, and extracellular matrix proteins. The main difference between the two processes relies in the mechanism of formation of capillaries. While vasculogenesis refers to in situ assembly of precursor cells into capillaries, angiogenesis represents the formation of new capillaries from preexisting vessels. ${ }^{36-39}$

Arteriogenesis is another complex process of vessel formation, which is fundamentally based on collateralization. Preexisting collateral vessels can enlarge up to 25 times their original size to facilitate increase in blood supply..$^{40}$ Arteriogenesis is associated with structural remodeling of the vessel and significant increase in the endoluminal shear stress, which in turn activates endothelial cells and triggers the release of factors that recruit monocytes to collaterals. ${ }^{36,41-45}$

Two methods have been proposed for achieving therapeutic angiogenesis: gene therapy and cell therapy (Figure 1). ${ }^{46,47}$ Each of them has encouraging preclinical results; however, while cell therapy seems to represent a promising approach, being associated with a moderate clinical improvement, gene therapy failed to convincingly demonstrate a substantial benefit in terms of clinical endpoints.

\section{Therapeutic angiogenesis}

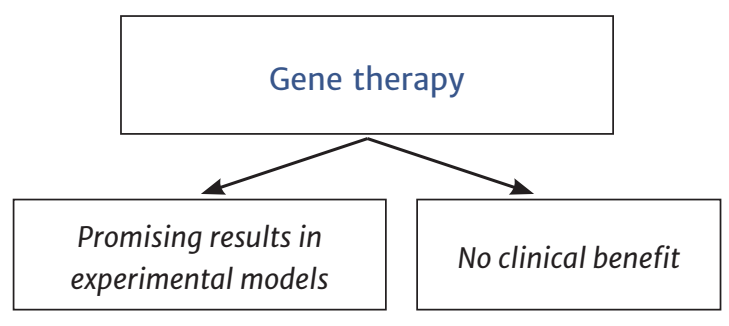

TRAFFIC - Recombinant Fibroblast Growth Factor

RAVE - Vascular Endothelial Growth Factor

TALISMAN 201 - NV1FGF

WALK - recombinant adenovirus vectors

VIROMED - hepatocyte growth factor

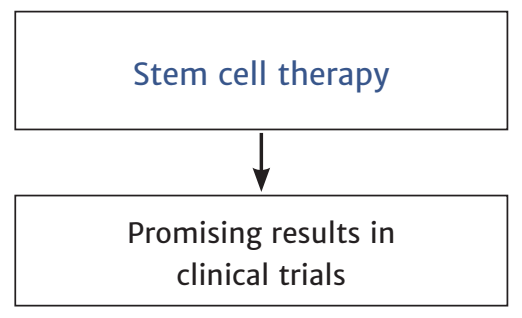

TACT - intramuscular

PROVASA - intra-arterial

RESTORE - CLI - intramuscular

FIGURE 1. Therapeutic angiogenesis - main approaches and clinical trials 


\section{GENE THERAPY FOR ISCHEMIC LIMBS}

Gene therapy in CLI is based on in vivo gene transfer and stimulation of angiogenesis using angiogenic growth factors such as vascular endothelial growth factor (VEGF), fibroblast growth factor (FGF), hepatocyte growth factor (HGF), hypoxia-inducible factor 1 alpha (HIF-1a), a.s.0. ${ }^{36,48-51}$ This approach demonstrated promising results in experimental models; however, clinical studies testing their role in limb salvage failed to demonstrate any clinical benefit.52,53 Several clinical studies showed that the transfer of proteins and genes to the human system is safe; however, they did not demonstrate any superiority against alternative strategies for limb salvage..$^{48}$

The TRAFFIC study (Therapeutic Angiogenesis with Recombinant Fibroblast growth Factor-2 for Intermittent Claudication), showed no statistically significant benefit in the walk distance in double dose vs. single dose vs. placebo group, after intra-arterial injection of recombinant-FGF2. ${ }^{54}$ RAVE (Regional Angiogenesis with Vascular Endothelial Growth Factor) was a phase 2, double-blind, placebo-controlled study, which also failed to demonstrate any benefit of adenoviral VEGF in intramuscular applications. Both the primary endpoint, consisting in peak walking distance at 12 weeks, and the secondary endpoints, represented by ankle-brachial index (ABI), claudication time, and quality of life (QoL), did not present any significant difference between the study groups..$^{55}$

Similarly, other clinical trials testing the role of plasmid-based fibroblast growth factor 1 in the TALISMAN 201 study, ${ }^{56}$ recombinant adenovirus vectors in the WALK study, ${ }^{57}$ hepatocyte growth factor in the VIROMED study, ${ }^{58}$ E2F transcriptor factor in the PREVENT III trial, or HGF plasmid in the HGF-STAT trial did not prove any benefit in clinical outcomes in patients with severely ischemic inferior limbs. ${ }^{59,60}$

\section{CELL THERAPY FOR ISCHEMIC LIMBS}

After the first description by Asahara, in 1997, of the potential of cells originating from the bone marrow (BM) to differentiate into endothelial cells, promote vessel growth, and stimulate vasculogenesis, many attempts have been made in order to validate these cells as a therapeutic agent. ${ }^{61}$

The concept of cell therapy in limb ischemia is based on the capacity of the bone marrow-derived progenitor cells to promote collateral vessel formation and neovascularization of ischemic tissue. ${ }^{62}$ Preclinical studies demonstrated the validity of this concept and, contrary to the discouraging results obtained with gene therapy in CLI in clinical settings, the strategy of using stem cells (SCs) for the stimulation of new vessel formation showed promising results in several clinical trials.

The main issues associated to stem cell (SC) therapy in CLI are related to their altered phenotype in patients with atherosclerotic disease and their different mobilization and functionalization, while open questions remain, even after large debates, regarding the source of cells, the amount of cells to be delivered, and the route of cell delivery. ${ }^{62}$

\section{MAJOR CONTROVERSIES IN SC THERAPY FOR CARDIOVASCULAR DISEASES - SIMILARITIES BETWEEN CARDIAC AND ARTERIAL APPLICATIONS}

\section{STEM CELL SOURCES}

One of the most debated issues in relation to SC applications for cardiovascular applications concerns the origin of the cells. A large number of different types of SCs have been used in clinical studies for SC therapy in post-myocardial infarction phase, while those generally used in patients with limb ischemia were cell lines originating from $\mathrm{BM}$, from peripheral blood, or with other origins. BMderived SCs (BM-SCs) comprise the group of autologous stem cells, bone marrow mononuclear cells (BM-MNCs), and endothelial progenitor cells (EPCs); peripheral blood-derived SCs include peripheral blood mononuclear cells (PB-MNCs) and circulating progenitor cells (CPCs), while the groups of cells with other origins include mesenchymal cells (MSCs) and adipose tissue-derived stem cells (ADSCs). ${ }^{14}$ Allogenic cells have also been produced in high-tech facilities and are available for clinical use; however, their main disadvantage is represented by the immune response that could be triggered by the host defense mechanism activated in the recipient in reaction to the allogenic nature of the cells. BM-SCs demonstrated significant safety outcomes; however, their use has been associated with many issues related to cell collection and mobilization. ${ }^{14}$ MSCs are multipotent cells with a high capacity of releasing soluble molecules, growth factors, and extracellular matrix components with significant benefic paracrine activity. ${ }^{14}$ However, it has been demonstrated that their secretory functionality and benefic effects decrease with age.

Several studies on BM-SCs demonstrated a clear benefit in clinical outcomes in patients with CLI, expressed by improvement of symptoms, increase in $\mathrm{ABI}$, increase in 
transcutaneous oxygen pressure $\left(\mathrm{TcPO}_{2}\right)$ and formation of new vessels. ${ }^{63-70}$ In diabetic patients, intra-arterial injections of BM-MNCs improved angiogenesis, generating a significant increase in the collateral network..$^{71}$ The same observation in diabetic patients was recorded by Huang et al., after intramuscular injection of GSF-mobilized autologous peripheral blood mononuclear cells. ${ }^{72}$ At the same time, an approach using peripheral blood CD34+/CD133+ cells after mobilization with G-CSF showed a significant increase in $\mathrm{ABI}$ and improvement in ulcer healing. ${ }^{73}$

Burt et al. demonstrated that injection of $\mathrm{CD}_{3} 4^{+} /$ CD133+ endothelial progenitor cells was associated with improvement in amputation-free survival, pain relief, exercise capacity, and QoL, in parallel with a significant stimulation of the process of collateral formation. ${ }^{74}$ Losordo et al., in a randomized, controlled, pilot study of autologous CD34+ cell therapy for CLI, showed that intramuscular injections of CDE34+ cells is safe and tend to reduce amputation rates. ${ }^{75}$

Stimulation of angiogenesis by BM-MNCs has also been proved by Dash et al., who recorded a significant improvement in pain relief, walking distance, and wound healing in patients undergoing cell therapy. ${ }^{76}$ In a small study by Huang et al., peripheral blood-derived SCs demonstrated a higher overall efficacy when compared with BM-derived SCs, in terms of ABI improvement, pain reduction, increase in walking distance, ulcer healing, and limb salvage. ${ }^{68}$

ADSCs, cardiac-derived SCs and human fetal-derived SCs have also been proposed as effective therapies for treating severe limb ischemia; however, their role remains to be established by further clinical studies. ${ }^{77}$ In a phase I trial published by Bura et al., autologous ADSCs were administered intramuscularly in each leg of patients with non-revascularizable arterial occlusions, demonstrating good feasibility and safety when using this source of cells. ${ }^{78}$ Another phase I study assessed the role of allogenic MSCs injected using intra-arterial route and demonstrated significant therapeutic benefits of this approach. ${ }^{79}$ However, the promising results of these studies should be further investigated in more advanced phase clinical trials.

So far, none of the SC groups has demonstrated a clear superiority over other types in patients with severe ischemia of the lower limbs.

\section{ROUTE OF CELL DELIVERY}

A large number of studies tried to identify the most effective route for SC injection. In cardiac applications, SCs have been mostly studied in the period following an acute myocardial infarction, in a hope that they will induce formation of new contractile myocytes able to replace the function of the infarcted ones. In the post-infarction period, SCs have been infused at the site of the infarction using intracoronary as well as intramyocardial injections. Recent data suggest that intramyocardial delivery of MSCs is more effective than intracoronary delivery in triggering the release of angiogenic factors. ${ }^{80}$ At the same time, a recent meta-analysis of individual patient data from randomized trials revealed that in patients with recent acute myocardial infarction, intracoronary cell therapy provided no significant clinical benefit in terms of clinical events or changes in left ventricular function. ${ }^{81}$

Similarly to cardiac studies, two injection routes have been tested in peripheral applications: intra-arterial and intramuscular route, respectively.

Intra-arterial route means injection of the SCs in the occluded artery, into the border of the ischemic region, usually proximal to the site of occlusion, in order to stimulate the development of collateral channels between the sites located proximal and distal to the occlusion, at the same time inducing formation of new vessels distal to the occlusion. The disadvantage of this method is that the mobility of cells from the arterial circulation to the inflammatory site is poor.

The intramuscular route follows a similar principle with the one used for the injection of SCs in the myocardial tissue, being represented by the injection of SCs in several locations in the gastrocnemius muscle following the anatomic course of the obstructed artery, creating local cellular islets with a significant paracrine effect. ${ }^{82}$

The main results of the clinical studies in SC therapy for CLI, using intramuscular and intra-arterial routes, are presented in Table 1. The main disadvantage of these studies is the limited sample size, which makes it difficult to reach statistical significance or to generalize the conclusions.

In intramuscular applications, the injection of autologous BM-MNCs was associated with a 3-year limb salvage rate of $60 \%$ in the TACT trial (Therapeutic Angiogenesis Using Cell Transplantation), while the BONMOT-1 trial (Bone Marrow Outcomes Trial 1) demonstrated a 6-month amputation-free rate of 59\%. ${ }^{91,92}$ Intra-arterial injection of BM-MNCs led to significant clinical improvement in the PROVASA trial (Intra-arterial Progenitor Cell Transplantation Bone Marrow Mononuclear Cells for Induction of Neovascularization in Patients with Peripheral Arterial Occlusive Disease), the results being largely dependent on the number of cells administrated and the number of injections. ${ }^{88}$ 
TABLE 1. Main clinical studies addressing SC therapy in severely ischemic limbs, using intramuscular and intra-arterial routes, and their clinical endpoints

\begin{tabular}{|c|c|c|}
\hline Clinical Study & Type of SC & Outcome measure/Clinical endpoint \\
\hline \multicolumn{3}{|l|}{ Intramuscular injection } \\
\hline Bura et al. ${ }^{78}, 2014$ & Adipose-derived SCs & Improved wound healing, feasibility, safety \\
\hline Takagi et al.83, 2014 & BM mononuclear cells & Clinical benefit, safety \\
\hline Amato et al. ${ }^{84}, 2012$ & BM-derived circulating endothelial progenitors & Improvement of quality of life \\
\hline Maksimov et al. ${ }^{85}, 2011$ & Autologous peripheral blood cells & Safety, effectiveness \\
\hline Tatieshi-Yuyama et al. ${ }^{86}, 2002$ & BM mononuclear cells & Safety, effectiveness \\
\hline Huang et al. ${ }^{72}, 2005$ & BM mononuclear cells & Pain reduction \\
\hline Prochazka et al. ${ }^{87}, 2010$ & Autologous mononuclear BM SCs & Limb salvage \\
\hline \multicolumn{3}{|l|}{ Intra-arterial injection } \\
\hline Das et al. $.^{79}, 2013$ & Allogenic mesenchymal SCs & Safety, effectiveness \\
\hline Ruiz-Salmeron et al. ${ }^{71}, 2011$ & Autologous mononuclear BM SCs & Safety, clinical outcomes \\
\hline Walter et al. ${ }^{88}, 2011$ & BM mononuclear cells & Safe, feasible, wound healing \\
\hline Cobellis et al. ${ }^{89}, 2005$ & Autologous mononuclear BM SCs & Increase capillary density, pain reduction \\
\hline \multicolumn{3}{|c|}{ Intra-arterial plus intramuscular injection } \\
\hline Franz et al.78, 2009 & Autologous BM-MNCs & No significant improvement in $\mathrm{ABI}$ \\
\hline Van Tongeren et al.90, 2008 & Autologous BM SC & Safety, limb salvage \\
\hline
\end{tabular}

Interestingly, in several studies, the clinical endpoints $\left(\mathrm{ABI}\right.$ and $\mathrm{TCPO}_{2}$ ) significantly improved only after intramuscular injection of SCs, either alone or in combination with intra-arterial injection, but not after intra-arterial injection alone. ${ }^{14,73,93,94}$

In a recently published meta-analysis of 19 randomized controlled trials including 837 patients, 7 non-randomized trials including 338 patients, and 41 non-controlled studies on 1,177 patients receiving intra-arterial or intramuscular cell therapy, Rigato et al. showed that cell therapy reduced the risk of amputation by $37 \%$ and improved wound healing by $59 \%$. There was also a significant improvement in clinical endpoints such as ABI, transcutaneous oxygen tension, and rest pain. In this meta-analysis, intramuscular implantation appeared more effective than intra-arterial infusion, and mobilized PB-MNCs seemed superior to BM-MNCs and MSCs in patients with severe ischemia of the lower limbs. ${ }^{95}$

\section{ALTERED RESPONSE TO SC THERAPY}

In a study by Idei et al., autologous SCs from patients with atherosclerotic diseases presented an altered phenotype, which was associated with worse outcomes compared to patients with Buerger disease, who demonstrated a preserved phenotype. ${ }^{96}$ This observation shows that patients with atherosclerotic disease could present an altered re- sponse to SC therapy, as a result of an impaired SC phenotype. Furthermore, other studies showed that BM-MNCs from patients with atherosclerotic disease present an altered capacity of neovascularization. ${ }^{97,98}$

In a pre-clinical study in pigs, absolute myocardial blood flow decreased significantly immediately after intracoronary injections of MSCs as compared with controls in closed-chest reperfused acute myocardial infarction $(42.0 \pm 12.4 \mathrm{~mL} / \mathrm{min}$ vs. $57.7 \pm 15.7 \mathrm{~mL} / \mathrm{min}, \mathrm{p}=0.013)$, showing an incomplete recovery at $24 \mathrm{~h}(47.2 \pm 5.5 \mathrm{~mL} /$ $\min$ vs. $62.1 \pm 14.1 \mathrm{~mL} / \mathrm{min}, \mathrm{p}=0.038$ ). This study proves that the delivery of SC into an injured tissue might be influenced by the altered flow conditions. ${ }^{99}$

Similarly to the observation noticed in coronary circulation, it would be logical to hypothesize that in patients with arterial occlusions there is a similar pattern of altered distribution of SCs in ischemic tissues. This is particularly relevant in CLI, a disease in which multiple severe lesions coexist in the arterial tree, leading to a more complex alteration of the arterial flow and consecutive severe ischemia of skeletal muscle fibers. However, there are very scarce data published so far to prove the role of various pathophysiological mechanisms related to an altered response to SC therapy in CLI.

An experimental study by Gremmels et al. investigated whether BM-SCs collected from patients with CLI are dysfunctional when compared to BM-SCs obtained from 
healthy subjects and showed that both cell populations have a similar ability to restore altered perfusion in $\mathrm{mu}-$ rine ischemic hind limbs. ${ }^{100}$

\section{THE ATHEROPROTECTIVE EFFECT OF SCS}

A serious concern related to SC therapy in cardiovascular applications has been raised by several authors who claimed that angiogenic factors could destabilize atherosclerotic plaques as a result of their angiogenic effects on vasa vasorum. ${ }^{48}$ However, no clinical experience confirmed this hypothesis.

Furthermore, in a computed tomography-controlled study, we proved that intracoronary injection of SCs is associated with a more effective protective effect on the vascular endothelium, leading to a significant reduction in plaque progression on long term. In this study, atheromatous plaque burden, as assessed by computed tomography angiography performed at 4 years after SC infusion, was significantly lower in coronary arteries infused with SCs compared to those untreated (112 $\pm 16 \mathrm{~mm} 3$ vs. $189 \pm 20.9$ $\mathrm{mm} 3, \mathrm{p}<0.0001$ ), while calcium scoring was $53.1 \pm 16.4$ vs. $106.43 \pm 10.86(\mathrm{p}<0.0001) .{ }^{101}$
However, little is known in present about the antiatherogenic, vasculoprotective effect of intracoronary or intra-arterial delivered SCs, and there are no studies yet to prove the effect of SCs on reducing atheromatous plaque vulnerability.

\section{CLINICAL OUTCOMES OF STEM CELL THERAPY IN CLI}

Different clinical endpoints have been used to validate the role of SCs in patients with severe limb ischemia, the most relevant ones including $\mathrm{ABI}, \mathrm{TcPO}_{2}$, limb salvage, wound healing, or pain reduction.

In a pilot study on 5 patients, we showed that injection of SCs using a combined approach (intra-arterial and intramuscular in the gastrocnemius muscles) can be associated with pain reduction and limb salvage at 2 years. At the same time, immunohistochemical analysis of samples of muscular tissue collected from the site of intramuscular injection at 6 months post injection demonstrated the presence of FLT1 - Vascular Endothelial Growth Factor Receptor-1 and of $\mathrm{CD} 34$ cells in the capillary endothelium of the newly formed vessels, as reliable markers of angio-
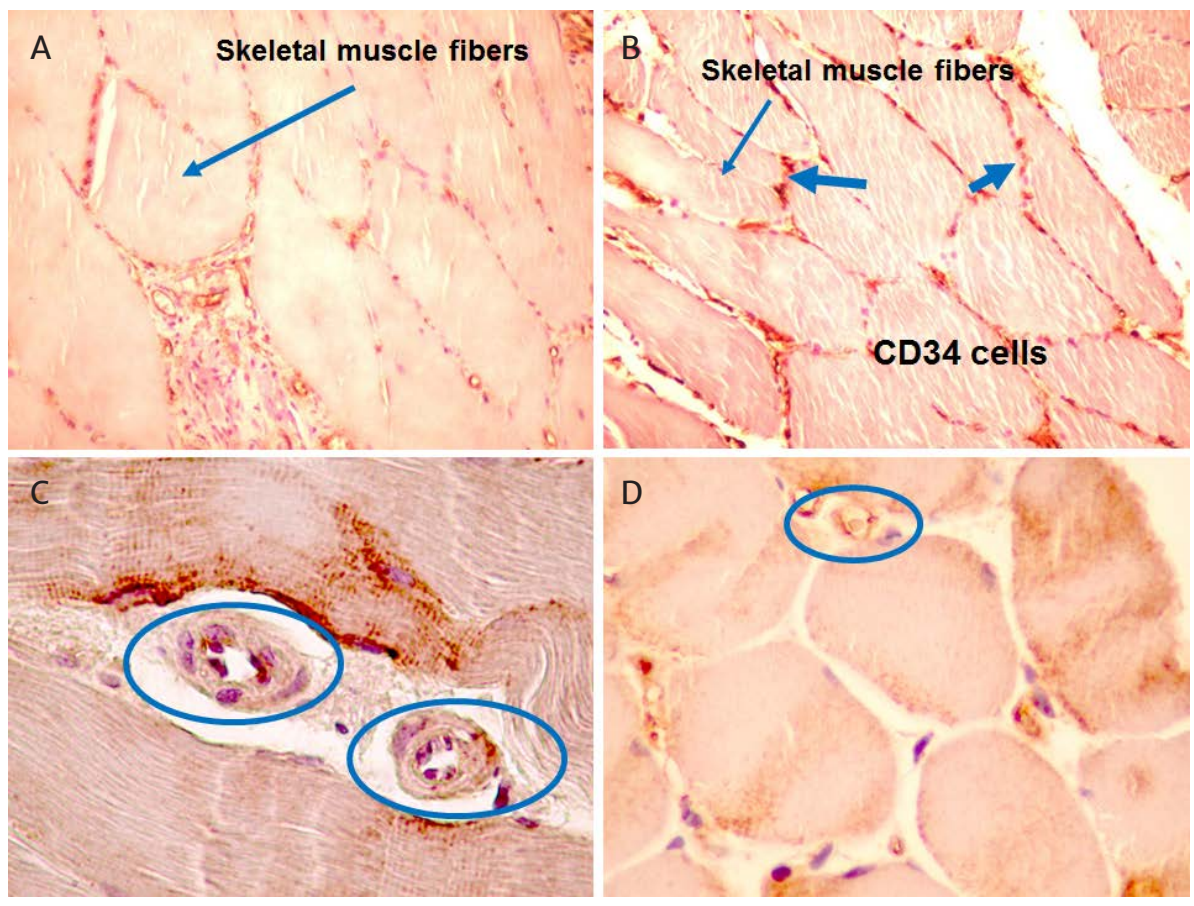

FIGURE 2. Analysis of samples of muscular tissue from biopsies collected at 6 months post intra-arterial and intramuscular SC injection. A - Muscular tissue before SC injection (thin arrow); B - Muscular biopsy post stem cell therapy - immunohistochemical analysis showing the presence of $\mathrm{CD} 34$ cells in the capillary endothelium of the newly formed vessels (large arrows); C and D - presence of the FLT1 - Vascular Endothelial Growth Factor Receptor-1 - indicator of angiogenesis (circle). 

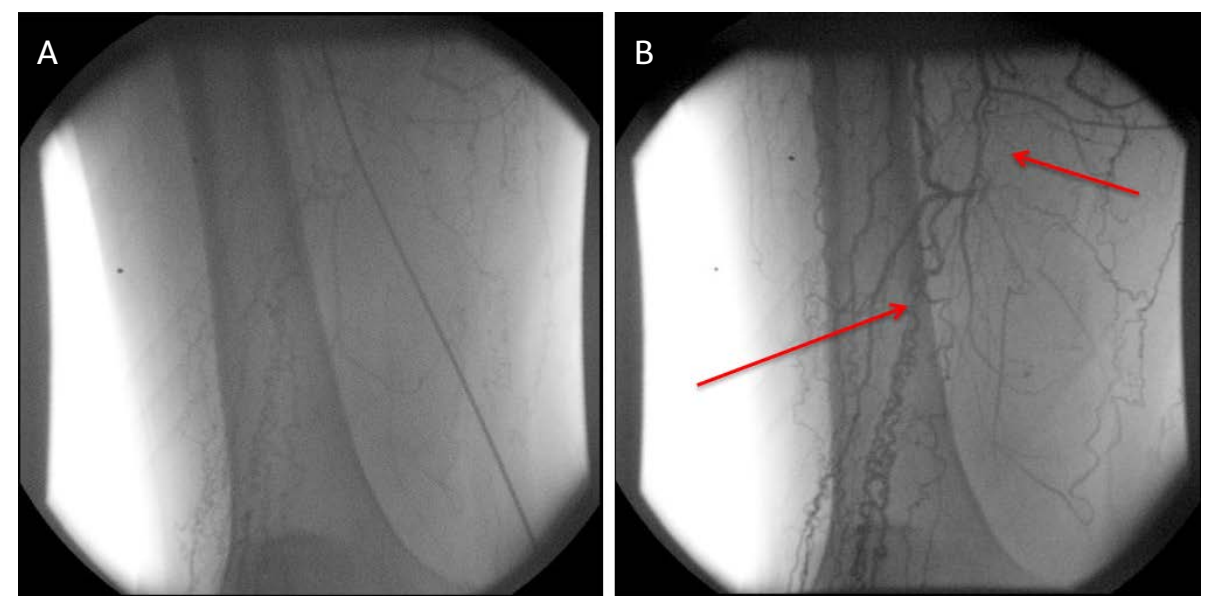

FIGURE 3. Peripheral angiography in a patient presenting with severe ischemia of the right inferior limb; A - before injection of SCs; B - 6 months after intra-arterial and intra-muscular injection of SCs, demonstrating a significant increase in collateral channels following SC injection (arrows).

genesis in the muscular tissue where SCs have been injected (Figure 2). Also, peripheral angiography, performed at 6 months post injection, demonstrated the presence of newly developed collateral channels distal to the intraarterial injection (Figure 3). All these preliminary results demonstrate that in CLI, SC therapy can induce angiogenesis and development of new collaterals, playing a definite role in limb salvage.

\section{CLINICAL TRIALS FOR SC THERAPY IN CLI}

TACT was the first published trial demonstrating the potential role of BM-MNCs in the treatment of CLI. In this trial, SC administration using the intramuscular route was associated with a $60 \%$ amputation-free rate at 3 years, a significant improvement in the leg pain scale, a significant reduction in ulcer size, and a significant increase in painfree walking distance. ${ }^{86}$

PROVASA was a clinical trial assessing the role of intraarterial injection of SCs for the treatment of CLI. ${ }^{87}$ The study enrolled 40 patients randomized to BM therapy vs. placebo. There was no significant difference in the eventfree survival rates; however, a non-significant improvement in the $\mathrm{ABI}$ was observed at 3 months following the injection of BM-MNCs, which was maintained during the follow-up. At the same time, complete ulcer healing was obtained in almost all the cases in the SC group and in only a few cases in the placebo group $(\mathrm{p}=0.03)$. However, $17 / 21(81 \%)$ of wound healing occurred only after repeated injections of BM-MNCs. Median ABI increased from 0.66 to 0.85 in the SC group, compared with a limited increase from 0.64 to 0.7 in the placebo group. This study demon- strated that intra-arterial administration of BM-MNCs is safe and feasible, and accelerates wound healing. ${ }^{88}$

The PROVASA trial attempted also to explore the role of various factors in generating a different response to SC therapy. Analysis of the reduction in absolute pain intensity in this trial showed that patients who received a repeated injection of BM-MNCs experienced a significantly higher reduction in pain scale, as compared with those who received a single dose of BM-MNCs $(p=0.1$ for single-dose vs. placebo and 0.002 for double-dose vs. placebo). The same was true for ischemic ulcer area, which significantly decreased in patients who received a repeated injection of BM-MNCs. ${ }^{88}$

Investigators of the PROVASA trial also analyzed the dose-related differences in patient subgroups and demonstrated that in patients with complete ulcer healing, the number of cells injected was significantly higher than in the non-healing group $(\mathrm{p}=0.003)$. At the same time, functional capacity of the injected SCs was significantly higher in the healing group $(\mathrm{p}=0.016)$. Multivariate analysis showed that the repeated BM-MNCs administration as well as the number and functionality of administered cells were the most significant independent predictors for clinical improvement (HR 1.02, 95\% CI 1.00-1.03, p = 0.003 for cell number, HR 6.17, 95\% CI 1.35-28, p $=0.018$ for $>2$ administrations of BM-MNCs, and HR 0.99, 95\% CI $0.98-1.0, p=0.049$ for cell function).$^{88}$

In a recently published study on 62 patients with CLI not eligible for revascularization, Madaric et al. also showed that the absolute number of injected BM-MNCs significantly correlated with the improvement of inflammation and with clinical outcomes. ${ }^{102}$ 
In a larger study on 143 patients with CLI, severe pain and non-healing ulcer, out of which 97 of atherosclerotic etiology and 46 with Buerger disease, who received intramuscular injection of BM-MNCs, there were significantly superior amputation-free survival rates in patients who received BM-MNCs therapy. Interestingly, the subgroup of patients with Buerger disease presented a significantly superior limb salvage rate at the 4-year follow-up as compared with patients with atherosclerotic disease (95\% vs. $48 \%$ ). At the same time, there was a superior improvement in other clinical endpoints such as the $\mathrm{ABI}, \mathrm{TcPO}_{2}$, and pain reduction pain in patients with Buerger disease following SC therapy. Furthermore, there was a superior cell migration in response to VEGF in patients with Buerger disease as compared with atherosclerotic ones ( $\mathrm{p}<0.0001)$, indicating that patients with Buerger disease might represent a class of better responders to SC therapy. ${ }^{96}$

In RESTORE-CLI, a phase 2, double-blind, placebocontrolled, randomized trial, the effect of intramuscular injection of an ixmyelocel-T multicellular solution of SCs was investigated in a lot of 86 patients who were injected in over 20 locations in a single leg. Ixmyelocel-T is a patient-specific multicellular solution with advanced properties of immune modulation and promotion of angiogenesis. ${ }^{103}$ In this trial, survival curves diverged early in the favor of the SC group, and the difference between groups was maintained during the 12-month follow-up, suggesting that ixmyelocel-T could represent a promising treatment option in patients with CLI and no option for revascularization. ${ }^{103}$

\section{STEM CELL THERAPY FOR WOUND HEALING IN CLI}

Another promising field for application of SCs in CLI is represented by the development of bioengineered tissues for wound care. Tissues impregnated with SCs cultured onto different scaffolds have been proposed to represent viable bioengineered skin substitutes for ischemic wounds unresponsive to conventional therapy. ${ }^{104}$ However, this technology requires sophisticated methodology for cell culture and scaffold impregnation, and still needs to be validated in future studies.

\section{CONCLUSION}

Therapeutic angiogenesis using stem cells is a promising therapeutic option in patients with severe limb ischemia who are not candidates for revascularization. The predictors of success for SC therapy are repeated administration as well as the number and viability of the administered cells. Initial clinical experience shows promising results in clinical trials on small sample sizes; however, larger trials are required in order to validate this therapy as a viable therapeutic option for patients with threatened ischemic limbs.

\section{ACKNOWLEDGEMENT}

This review study was partially supported by the research grant TRANSCARDIOSTEM, financed by the Romanian Ministry of Research (contract no. CEEX-72-2005), as well as by the resources and the use of facilities at the Cardio Med Medical Center, Tîrgu Mureș, Romania.

\section{CONFLICT OF INTEREST}

Nothing to disclose.

\section{REFERENCES}

1. Patel MR, Conte MS, Cutlip DE, et al. Evaluation and treatment of patients with lower extremity peripheral artery disease: consensus definitions from Peripheral Academic Research Consortium (PARC). J Am Coll Cardiol. 2015;65:931-941. doi: 10.1016/j.jacc.2014.12.036.

2. Dua A, Lee CJ. Epidemiology of Peripheral Arterial Disease and Critical Limb Ischemia. Tech Vasc Interv Radiol. 2016;19:9195. doi: 10.1053/j.tvir.2016.04.001.

3. Eraso LH, Fukaya E, Mohler ER III., Xie D, Sha D, Berger JS. Peripheral arterial disease, prevalence and cumulative risk factor profile analysis. Eur J Prev Cardiol. 2014;21:704-711. doi:10.1177/2047487312452968.

4. Fowkes F, Rudan D, Rudan I, et al. Comparison of global estimates of prevalence and risk factors for peripheral artery disease in 2000 and 2010: a systematic review and analysis. Lancet. 2013;382:1329-1340. doi: http://dx.doi.org/10.1016/ S0140-6736(13)61249-0.

5. Varu VN, Hogg ME, Kibbe MR. Critical limb ischemia. J Vasc Surg. 2010;51:230-241. doi: 10.1016/j.jvs.2009.08.073.

6. Abu Dabrh AM, Steffen MW, Undavalli C, et al. The natural history of untreated severe or critical limb ischemia. J Vasc Surg. 2015;62:1642-1651. doi: 10.1016/j.jvs.2015.07.065.

7. Becker F, Robert-Ebadi H, Ricco JB, et al. Chapter I: definitions, epidemiology, clinical presentation and prognosis. Eur J Vasc Endovasc Surg. 2011;42:S4-S12. doi: 10.1016/S10785884(11)60009-9.

8. Shishehbor MH, White CJ, Gray BH, Menard MT, Lookstein R, Jaff MR. Critical Limb Ischemia: An Expert Statement. J Am Coll Cardiol. 2016;68:2002-2015. doi:10.1016/j. jacc.2016.04.071.

9. Dattilo PB, Casserly IP. Critical limb ischemia: endovascular strategies for limb salvage. Prog Cardiovasc Dis. 2011;54:4760. doi: 10.1016/j.pcad.2011.02.009.

10. Mandolfino T, Canciglia A, Lamberto S, Calogero S, D'Alfonso $\mathrm{M}$, Bottari A. Extreme endovascular revascularization for limb salvage in critical limb ischemia. Int Angiol. 2012;31:163-168. 
11. Callum K, Bradbury A. Acute limb ischaemia. BMJ : British Medical Journal. 2000;320:764-767.

12. Beyersdorf F, Schlensak C. Controlled reperfusion after acute and persistent limb ischemia. Semin Vasc Surg. 2009;22:5257. doi: 10.1053/j.semvascsurg.2009.01.005.

13. Gilliland C, Shah J, Martin JG, Miller MJ Jr. Acute Limb Ischemia. Tech Vasc Interv Radiol. 2017;20:274-280. doi: 10.1053/j.tvir.2017.10.008.

14. Compagna R, Amato B, Massa S, et al. Cell Therapy in Patients with Critical Limb Ischemia. Stem Cells Int. 2015;2015:931420. doi: $10.1155 / 2015 / 931420$.

15. Simons JP, Goodney PP, Nolan BW, et al. Failure to achieve clinical improvement despite graft patency in patients undergoing infrainguinal lower extremity bypass for critical limb ischemia. J Vasc Surg. 2010;51:1419-1424. doi: 10.1016/j. jvs.2010.01.083.

16. Lawall H, Bramlage $\mathrm{P}$, Amann B. Stem cell and progenitor cell therapy in peripheral artery disease. A critical appraisal. Thromb Haemost. 2010;103:696-709. doi: 10.1160/THo9-100688.

17. Adam DJ, Beard JD, Cleveland T, Bell J, Bradbury AW, Forbes JF. Bypass versus angioplasty in severe ischaemia of the leg (BASIL): multicentre, randomised controlled trial. Lancet. 2005;366:1925-1934. doi: 10.1016/S0140-6736(05)67704-5.

18. Fowkes FG, Murray GD, Butcher I, et al. Ankle brachial index combined with Framingham Risk score to predict cardiovascular events and mortality: a meta-analysis. JAMA. 2008;300:197-208. doi: 10.1001/jama.300.2.197.

19. Kum S, Tan YK, Schreve MA, et al. Midterm Outcomes From a Pilot Study of Percutaneous Deep Vein Arterialization for the Treatment of No-Option Critical Limb Ischemia. J Endovasc Ther. 2017;24:619-626. doi: 10.1177/1526602817719283.

20. Chen XP, Fu WM, Gu W. Spinal Cord stimulation for patients with inoperable chronic critical leg ischemia. World J Emerg Med. 2011;2:262-266. doi: 10.5847/ wjem.j.1920-8642.2011.04.003.

21. Walker C. Pedal access in critical limb ischemia. J Cardiovasc Surg (Torino). 2014;55:225-227.

22. Tawfick WA, Hamada N, Soylu E, Fahy A, Hynes N, Sultan S. Sequential compression biomechanical device versus primary amputation in patients with critical limb ischemia. Vasc Endovascular Surg. 2013;47:532-539. doi: 10.1177/1538574413499413.

23. Qadura M, Terenzi DC, Verma S, Al-Omran M, Hess DA. Cell Therapy for Critical Limb Ischemia: An Integrated Review of Pre-clinical and Clinical Studies. Stem Cells. 2017; doi: 10.1002/stem.2751. [Epub ahead of print]

24. Pignon B, Sevestre MA, Kanagaratnam L, et al. Autologous Bone Marrow Mononuclear Cell Implantation and Its Impact on the Outcome of Patients With Critical Limb Ischemia Results of a Randomized, Double-Blind, Placebo-Controlled Trial. Circ J. 2017;81:1713-1720. doi: 10.1253/circj.CJ-17-0045.

25. Ismail AM, Abdou SM, Aty HA, etal.Autologous transplantation of $\mathrm{CD} 34(+)$ bone marrow derived mononuclear cells in management of non-reconstructable critical lower limb ischemia. Cytotechnology. 2016;68:771-781. doi: 10.1007/ s10616-014-9828-7.

26. Perotti C, Arici V, Cervio M, et al. Allogeneic lethally irradiated cord blood mononuclear cells in no-option critical limb ischemia: a "box of rain". Stem Cells Dev. 2013;22:28062812. doi: 10.1089/scd.2013.0172.
27. Liew A, O'Brien T. Therapeutic potential for mesenchymal stem cell transplantation in critical limb ischemia. Stem Cell Res Ther. 2012;3:28. doi: 10.1186/scrt119.

28. Koshikawa M, Shimodaira S, Yoshioka T, et al. Therapeutic angiogenesis by bone marrow implantation for critical hand ischemia in patients with peripheral arterial disease: a pilot study. Curr Med Res Opin. 2006;22:793-798. doi: 10.1185/030079906X1000078.

29. Hernández P1, Cortina L, Artaza H, et al. Autologous bonemarrow mononuclear cell implantation in patients with severe lower limb ischaemia: a comparison of using blood cell separator and Ficoll density gradient centrifugation. Atherosclerosis. 2007;194:e52-56. doi: 10.1016/j. atherosclerosis.2006.08.025.

30. Lachmann N, Nikol S. Therapeutic angiogenesis for peripheral artery disease: stem cell therapy. Vasa. 2007;36:241-251. doi:10.1024/0301-1526.36.4.241.

31. Napoli C, Farzati B, Sica V, et al. Beneficial effects of autologous bone marrow cell infusion and antioxidants/Larginine in patients with chronic critical limb ischemia. Eur J Cardiovasc Prev Rehabil. 2008;15:709-718. doi: 10.1097/ HJR.obo13e3283193aof.

32. Risau W. Mechanisms of angiogenesis. Nature. 1997;386:671674. doi: 10.1038/386671ao.

33. Ouma GO, Zafrir B, Mohler ER 3rd, Flugelman MY. Therapeutic angiogenesis in critical limb ischemia. Angiology. 2013;64:466-480. doi: 10.1177/0003319712464514.

34. Annex BH. Therapeutic angiogenesis for critical limb ischaemia. Nat Rev Cardiol. 2013;10:387-396. doi: 10.1038/ nrcardio.2013.70.

35. Carmeliet P. Mechanisms of angiogenesis and arteriogenesis. Nat Med. 2000;6:389-395.

36. Davies MG. Criticial Limb Ischemia: Epidemiology. Methodist DeBakey Cardiovascular Journal. 2012;8:10-14.

37. Ribatti D, Vacca A, Nico B, Presta M, Roncali L. Angiogenesis: basic and clinical aspects. Ital J Anat Embryol. 2003;108:1-24.

38. Semenza GL. Vasculogenesis, angiogenesis, and arteriogenesis: mechanisms of blood vessel formation and remodeling. J Cell Biochem. 2007;102:840-847. doi: 10.1002/ jcb.21523.

39. Axnick J, Lammert E. Vascular lumen formation. Curr Opin Hematol. 2012;19:192-198. doi: 10.1097/ MOH.obo13e3283523ebc.

40. Zhu S, Liu X, Li Y, Goldschmidt-Clermont PJ, Dong C. Aging in the atherosclerosis milieu may accelerate the consumption of bone marrow endothelial progenitor cells. Arterioscler Thromb Vasc Biol. 2007;27:113-119. doi: 10.1161/01. ATV.0000252035.12881.do.

41. van Royen N, Piek JJ, Buschmann I, Hoefer I, Voskuil M, Schaper W. Stimulation of arteriogenesis; a new concept for the treatment of arterial occlusive disease. Cardiovasc Res. 2001;49:543-553.

42. Helisch A, Schaper W. Arteriogenesis: the development and growth of collateral arteries. Microcirculation. 2003;10:8397. doi: 10.1038/sj.mn.7800173.

43. Cai W, Schaper W. Mechanisms of arteriogenesis. Acta Biochim Biophys Sin (Shanghai). 2008;40:681-92.

44. Fung E, Helisch A. Macrophages in Collateral Arteriogenesis. Frontiers in Physiology. 2012;3:353. doi:10.3389/ fphys.2012.00353. 
45. Jaipersad AS, Lip GY, Silverman S, Shantsila E. The role of monocytes in angiogenesis and atherosclerosis. J Am Coll Cardiol. 2014;63:1-11. doi: 10.1016/j.jacc.2013.09.019.

46. Sanada F, Taniyama Y, Azuma J, et al. Therapeutic Angiogenesis by Gene Therapy for Critical Limb Ischemia: Choice of Biological Agent. Immunology, Endocrine \& Metabolic Agents in Medicinal Chemistry. 2014;14:32-39. doi :10.2174/1871522213999131231105139.

47. Liew A, Bhattacharya V, Shaw J, Stansby G. Cell Therapy for Critical Limb Ischemia: A Meta-Analysis of Randomized Controlled Trials. Angiology. 2016;67:444-455. doi: 10.1177/0003319715595172.

48. Tongers J, Roncalli JG, Losordo DW. Therapeutic angiogenesis for critical limb ischemia: microvascular therapies coming of age. Circulation. 2008;118:9-16. doi: 10.1161/ CIRCULATIONAHA.108.784371.

49. Cross MJ, Claesson-Welsh L. FGF and VEGF function in angiogenesis: signalling pathways, biological responses and therapeutic inhibition. Trends Pharmacol Sci. 2001;22:201207.

50. Ho TK, Rajkumar V, Ponticos $M$, et al. Increased endogenous angiogenic response and hypoxia-inducible factor-1alpha in human critical limb ischemia. J Vasc Surg. 2006;43:125-133. doi: 10.1016/j.jvs.2005.08.042.

51. Henning RJ. Therapeutic angiogenesis: angiogenic growth factors for ischemic heart disease. Future Cardiol. 2016;12:585-599. doi: 10.2217/fca-2016-0006.

52. Tille JC, Wood J, Mandriota SJ, et al. Vascular endothelial growth factor (VEGF) receptor-2 antagonists inhibit VEGFand basic fibroblast growth factor-induced angiogenesis in vivo and in vitro. J Pharmacol Exp Ther. 2001;299:1073-1085.

53. Kim SK, Lee J, Song $M$, et al. Combination of three angiogenic growth factors has synergistic effects on sprouting of endothelial cell/mesenchymal stem cell-based spheroids in a 3D matrix. J Biomed Mater Res B Appl Biomater. 2016;104:1535-1543. doi: 10.1002/jbm.b.33498.

54. Lederman RJ, Mendelsohn FO, Anderson RD, et al. Therapeutic angiogenesis with recombinant fibroblast growth factor-2 for intermittent claudication (the TRAFFIC study): a randomised trial. Lancet. 2002;359:2053-2058.

55. Rajagopalan S, Mohler E 3rd, Lederman RJ, et al. Regional Angiogenesis with Vascular Endothelial Growth Factor (VEGF) in peripheral arterial disease: Design of the RAVE trial. Am Heart J. 2003;145:1114-1118. doi: 10.1016/So0028703(03)00102-9.

56. Nikol S, Baumgartner I, Van Belle E, et al. Therapeutic angiogenesis with intramuscular NV1FGF improves amputation-free survival in patients with critical limb ischemia. Mol Ther. 2008;16:972-978. doi: 10.1038/ mt.2008.33.

57. Creager MA, Olin JW, Belch JJ, et al. Effect of hypoxia-inducible factor-1alphagene therapy on walking performancein patients with intermittent claudication. Circulation. 2011;124:17651773. doi: 10.1161/CIRCULATIONAHA.110.009407.

58. Gu Y, Zhang J, Guo L, Cui S, Li X, Ding D, et al. A phase $\underline{I}$ clinical study of naked DNA expressing two isoforms of hepatocyte growth factor to treat patients with critical limb ischemia. J Gene Med. 2011;13:602-610. doi: 10.1002/jgm.1614.

59. Conte MS, Bandyk DF, Clowes AW, et al. Results of PREVENT III: a multicenter, randomized trial of edifoligide for the prevention of vein graft failure in lower extremity bypass surgery. J Vasc Surg. 2006;43:742-751. doi: 10.1016/j jvs.2005.12.058.

60. Comerota AJ, Throm RC, Miller KA, et al. Naked plasmid DNA encoding fibroblast growth factor type 1 for the treatment of end-stage unreconstructible lower extremity ischemia: preliminary results of a phase I trial. J Vasc Surg. 2002;35:930-936.

61. Asahara T, Murohara T, Sullivan A, et al. Isolation of putative progenitor endothelial cells for angiogenesis. Science. 1997;275:964-967.

62. Gupta R, Losordo DW. Cell Therapy for Critical Limb Ischemia Moving Forward One Step at a Time. Circ Cardiovasc Interv. 2011;4:2-5. doi: 10.1161/CIRCINTERVENTIONS.110.960716.

63. Nizankowski R, Petriczek T, Skotnicki A, Szczeklik A. The treatment of advanced chronic lower limb ischaemia with marrow stem cell autotransplantation. Kardiol Pol. 2005;63:351-360.

64. Tanaka M, Taketomi K, Yonemitsu Y. Therapeutic angiogenesis: recent and future prospects of gene therapy in peripheral artery disease. Curr Gene Ther. 2014;14:300-308.

65. Procházka V, Gumulec J, Chmelová J, et al. Autologous bone marrow stem cell transplantation in patients with end-stage chronical critical limb ischemia and diabetic foot. Vnitr Lek. 2009;55:173-178.

66. Brewster L, Robinson S, Wang R, et al. Expansion and angiogenic potential of mesenchymal stem cells from patients with critical limb ischemia. J Vasc Surg. 2017;65:826-838. doi: 10.1016/j.jvs.2015.02.061.

67. Kawamura A, Horie T, Tsuda I, et al. Clinical study of therapeutic angiogenesis by autologous peripheral blood stem cell (PBSC) transplantation in 92 patients with critically ischemic limbs. J Artif Organs. 2006;9:226-233. doi: 10.1007/ s10047-006-0351-2.

68. Huang PP, Yang XF, Li SZ, Wen JC, Zhang Y, Han ZC. Randomised comparison of G-CSF-mobilized peripheral blood mononuclear cells versus bone marrow-mononuclear cells for the treatment of patients with lower limb arteriosclerosis obliterans. Thromb Haemost. 2007;98:13351342.

69. Botti C, Maione C, Coppola A, Sica V, Cobellis G. Autologous bone marrow cell therapy for peripheral arterial disease. Stem Cells and Cloning: Advances and Applications. 2012;5:5-14. doi:10.2147/SCCAA.S28121.

70. Motukuru V, Suresh KR, Vivekanand V, Raj S, Girija KR. Therapeutic angiogenesis in Buerger's disease (thromboangiitis obliterans) patients with critical limb ischemia by autologous transplantation of bone marrow mononuclear cells. J Vasc Surg. 2008;48:53S-60S. doi: 10.1016/j.jvs.2008.09.005

71. Ruiz-Salmeron R, de la Cuesta-Diaz A, Constantino-Bermejo $M$, et al. Angiographic demonstration of neoangiogenesis after intra-arterial infusion of autologous bone marrow mononuclear cells in diabetic patients with critical limb ischemia. Cell Transplant. 2011;20:1629-1639. doi: 10.3727/096368910X0177.

72. Huang P, Li S, Han M, Xiao Z, Yang R, Han ZC. Autologous transplantation of granulocyte colony-stimulating factor-mobilized peripheral blood mononuclear cells

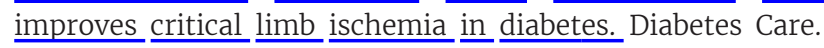
2005;28:2155-2160. 
73. Lara-Hernandez R, Lozano-Vilardell $\mathrm{P}$, Blanes $\mathrm{P}$, Torreguitart-Mirada N, Galmés A, Besalduch J. Safety and efficacy of therapeutic angiogenesis as a novel treatment in patients with critical limb ischemia. Ann Vasc Surg. 2010;24:287-294. doi: 10.1016/j.avsg.2009.10.012.

74. Burt RK, Testori A, Oyama Y, et al. Autologous peripheral blood CD133+ cell implantation for limb salvage in patients with critical limb ischemia. Bone Marrow Transplant. 2010;45:111-116. doi: 10.1038/bmt.2009.102.

75. Losordo DW, Kibbe MR, Mendelsohn F, et al. A Randomized, Controlled Pilot Study of Autologous CD34+ Cell Therapy for Critical Limb Ischemia. Circulation Cardiovascular interventions. 2012;5:821-830. doi:10.1161/ CIRCINTERVENTIONS.112.968321.

76. Dash NR, Dash SN, Routray P, Mohapatra S, Mohapatra PC. Targeting nonhealing ulcers of lower extremity in human through autologous bone marrow-derived mesenchymal stem cells. Rejuvenation Res. 2009;12:359-366. doi: 10.1089/ rej.2009.0872.

77. Yan J, Tie G, Xu TY, Cecchini K, Messina LM. Mesenchymal stem cells as a treatment for peripheral arterial disease: current status and potential impact of type II diabetes on their therapeutic efficacy. Stem Cell Rev. 2013;9:360-372. doi: 10.1007/s12015-013-9433-8.

78. Bura A, Planat-Benard V, Bourin P, et al. Phase I trial: the use of autologous cultured adipose-derived stroma/stem cells to treat patients with non-revascularizable critical limb ischemia. Cytotherapy. 2014;16:245-257. doi: 10.1016/j. jcyt.2013.11.011.

79. Das AK, Bin Abdullah BJ, Dhillon SS, Vijanari A, Anoop CH, Gupta PK. Intra-arterial allogeneic mesenchymal stem cells for critical limb ischemia are safe and efficacious: report of a phase I study. World J Surg. 2013;37:915-922. doi: 10.1007/ s00268-012-1892-6.

80. Gyöngyösi M, Hemetsberger R, Wolbank S, et al. Delayed recovery of myocardial blood flow after intracoronary stem cell administration. Stem Cell Rev. 2011;7:616-623. doi: 10.1007/s12015-010-9213-7.

81. Gyöngyösi M, Wojakowski W, Lemarchand $\mathrm{P}$, et al. MetaAnalysis of Cell-based CaRdiac stUdiEs (ACCRUE) in patients with acute myocardial infarction based on individual patient data. Circ Res. 2015;116:1346-1360. doi: 10.1161/ CIRCRESAHA.116.304346.

82. Moazzami K, Majdzadeh R, Nedjat S. Local intramuscular transplantation of autologous mononuclear cells for critical lower limb ischaemia. Cochrane Database Syst Rev. 2011;12:CD008347. doi: 10.1002/14651858.CDo08347.pub2.

83. Takagi G, Miyamoto M, Tara S, et al. Therapeutic vascular angiogenesis for intractable macroangiopathy-related digital ulcer in patients with systemic sclerosis: a pilot study. Rheumatology (Oxford). 2014;53:854-859. doi: 10.1093/ rheumatology/ket432.

84. Amato B, Compagna R, Della Corte GA, et al. Peripheral blood mono-nuclear cells implantation in patients with peripheral arterial disease: a pilot study for clinical and biochemical outcome of neoangiogenesis. BMC Surgery. 2012;12:S1. doi:10.1186/1471-2482-12-S1-S1.

85. Maksimov AV, Kiiasov AP, Plotnikov MV, et al. Outcomes of using autologous peripheral-blood stem cells in patients with chronic lower arterial insufficiency. Angiol Sosud Khir. 2011;17:11-15.
86. Tateishi-Yuyama E, Matsubara H, Murohara T, et al. Therapeutic angiogenesis for patients with limb ischaemia by autologous transplantation of bone-marrow cells: a pilot study and a randomised controlled trial. Lancet. 2002;360:427-435. doi: 10.1016/S0140-6736(02)09670-8.

87. Procházka V, Gumulec J, Jalůvka F, et al. Cell therapy, a new standard in management of chronic critical limb ischemia and foot ulcer. Cell Transplant. 2010;19:1413-1424. doi: 10.3727/096368910X514170.

88. Walter DH, Krankenberg H, Balzer JO, et al. Intraarterial administration of bone marrow mononuclear cells in patients with critical limb ischemia: a randomized-start, placebocontrolled pilot trial (PROVASA). Circ Cardiovasc Interv. 2011;4:26-37. doi: 10.1161/CIRCINTERVENTIONS.110.958348.

89. Cobellis G, Silvestroni A, Lillo S, et al. Long-term effects of repeated autologous transplantation of bone marrow cells in patients affected by peripheral arterial disease. Bone Marrow Transplant. 2008;42:667-672. doi: 10.1038/bmt.2008.228.

90. Van Tongeren RB, Hamming JF, Fibbe WE, et al. Intramuscular or combined intramuscular/intra-arterial administration of bone marrow mononuclear cells: a clinical trial in patients with advanced limb ischemia. J Cardiovasc Surg (Torino). 2008;49:51-58.

91. Matoba S, Tatsumi T, Murohara T, et al. Long-term clinical outcome after intramuscular implantation of bone marrow mononuclear cells (Therapeutic Angiogenesis by Cell Transplantation [TACT] trial) in patients with chronic limb ischemia. Am Heart J. 2008;156:1010-1018. doi: 10.1016/j. ahj.2008.06.025.

92. Amann B, Luedemann C, Ratei R, Schmidt-Lucke JA. Autologous bone marrow cell transplantation increases leg perfusion and reduces amputations in patients with advanced critical limb ischemia due to peripheral artery disease. Cell Transplant. 2009;18:371-380.

93. Lawall H, Bramlage P, Amann B. Treatment of peripheral arterial disease using stem and progenitor cell therapy. J Vasc Surg. 2011;53:445-453. doi: 10.1016/j.jvs.2010.08.060.

94. Dhong Z, Chen B, Fu W, et al. Transplantation of purified $\mathrm{CD} 34+$ cells in the treatment of critical limb ischemia. Journal of Vascular Surgery. 2013;58:404-411. doi: http://dx.doi. org/10.1016/j.jvs.2013.01.037.

95. Rigato M, Monami M, Fadini GP. Autologous Cell Therapy for Peripheral Arterial Disease: Systematic Review and MetaAnalysis of Randomized, Nonrandomized, and Noncontrolled Studies. Circ Res. 2017;120:1326-1340. doi: 10.1161/ CIRCRESAHA.116.309045.

96. Idei N, Soga J, Hata $\mathrm{T}$, et al. Autologous bone-marrow mononuclear cell implantation reduces long-term major amputation risk in patients with critical limb ischemia: a comparison of atherosclerotic peripheral arterial disease and Buerger disease. Circ Cardiovasc Interv. 2011;4:15-25. doi: 10.1161/CIRCINTERVENTIONS.110.955724.

97. Heeschen C, Lehmann R, Honold J, et al. Profoundly reduced neovascularization capacity of bone marrow mononuclear cells derived from patients with chronic ischemic heart disease. Circulation. 2004;109:1615-1622. doi: 10.1161/01. CIR.0000124476.32871.E3.

98. Li TS, Kubo M, Ueda K, et al. Identification of risk factors related to poor angiogenic potency of bone marrow cells from different patients. Circulation. 2009;120:S255-261. doi: 10.1161/CIRCULATIONAHA.108.837039. 
99. Gyöngyösi M, Hemetsberger R, Posa A, et al. Hypoxiainducible factor 1-alpha release after intracoronary versus intramyocardial stem cell therapy in myocardial infarction. J Cardiovasc Transl Res. 2010;3:114-121. doi: 10.1007/s12265009-9154-1.

100. Gremmels H, Teraa M, Quax PH, den Ouden K, Fledderus JO, Verhaar MC. Neovascularization capacity of mesenchymal stromal cells from critical limb ischemia patients is equivalent to healthy controls. Mol Ther. 2014;22:1960-1970. doi: 10.1038/mt.2014.161.

101. Benedek I, Bucur O, Benedek T. Intracoronary infusion of mononuclear bone marrow-derived stem cells is associated with a lower plaque burden after four years. J Atheroscler Thromb. 2014;21:217-229.
102. Madaric J, Klepanec A, Valachovicova M, et al. Characteristics of responders to autologous bone marrow cell therapy for nooption critical limb ischemia. Stem Cell Res Ther. 2016;7:116. doi: 10.1186/s13287-016-0379-z.

103. Powell RJ, Marston WA, Berceli SA, et al. Cellular therapy with Ixmyelocel-T to treat critical limb ischemia: the randomized, double-blind, placebo-controlled RESTORE-CLI trial. Mol Ther. 2012;20:1280-1286. doi: 10.1038/mt.2012.52.

104. Jadlowiec C, Brenes RA, Li X, et al. Stem cell therapy for critical limb ischemia: what can we learn from cell therapy for chronic wounds? Vascular. 2012;20:284-289. doi: 10.1258/ vasc.2011.201206. 